\title{
Influence of Critical Plasma Spray Parameters on the Properties of Plasma Sprayed Coatings Prepared from Spray Dried Alumina Powder
}

\author{
S.T. Aruna*, N. Balaji \\ Surface Engineering Division, \\ Council of Scientific and Industrial Research-National Aerospace Laboratories, \\ HAL Airport Road, Bangalore 560017, India
}

\section{Abstract:}

Plasma sprayable $\alpha$-alumina powder was prepared by spray drying process. The powder was characterized by field emission scanning electron microscopy (FESEM), powder X-ray diffractometry, particle size analysis and flowability measurement. In the present work, the influence of three different critical plasma spray parameter (CPSP) values $(675,825$ and 937.5 W/nl.pm) on the crystallographic forms, microstructure, microhardness, surface roughness, wear and corrosion resistance of the plasma sprayed alumina coatings were investigated. The coatings were characterized by X-ray diffractometry and the analysis revealed the presence of some traces of $\gamma$-alumina along with $\alpha$-alumina for the coating obtained at higher CPSP. The surface roughness, microhardness, corrosion and wear resistance of the coatings were evaluated. Plasma sprayed alumina coating obtained at the highest CPSP exhibited improved wear and corrosion resistance compared to the other two coatings which is attributed to the dense nature of the coating.

Key words: alumina; spray drying; plasma spraying; wear; microstructure

* Corresponding author

Tel.: +9180 25086250

Fax: (080) 2521-0113

\section{E-mail address: aruna_reddy @ nal.res.in}


28 Corrosion and wear problems are still of great relevance in a wide range of industrial 29 applications and products as they result in the degradation and eventual failure of components 30 and systems both in the processing and manufacturing industries and in the service life of many components. Various technologies have been used to deposit the appropriate surface protection

32 that can resist the degradations. Among these, thermal spraying especially plasma spraying is often considered as a potential alternative to traditional coating manufacturing techniques (such 34 as hard chrome electroplating) for the production of wear-resistant coatings ${ }^{[1-6]}$. Since the 1960 s 35 atmospheric plasma spraying (APS) has been widely used in industry and found applications in 36 many fields like automotive, aeronautical, medical, and paper milling ${ }^{[7-9]}$. As far as anticorrosion 37 and antiwear applications are concerned, the most frequently used coating materials are oxide 38 ceramic coatings ${ }^{[5]}$. ceramic material which has many technological applications. Plasma-sprayed aluminum oxide

$41\left(\mathrm{Al}_{2} \mathrm{O}_{3}\right)$ coatings offer excellent wear resistance, corrosion resistance, heat, and thermal shock 42 resistance, and have been widely used by the US Navy and other industries ${ }^{[7]}$. 43 Plasma sprayed alumina $\left(\mathrm{Al}_{2} \mathrm{O}_{3}\right)$ coatings have been used for many applications in textile, 44 electronic, aerospace, and aircraft industries because of their dielectric and wear resistance 45 properties and also nuclear industry ${ }^{[10,11]}$. Alumina coatings have several special properties like 46 high hardness, chemical inertness; wear resistance and high melting point. It is reported that the 47 corrosion resistance of alumina coatings are higher than that of cermet and metallic coatings ${ }^{[12,}$ $48^{13}$. Improved wear resistance has been reported for the alumina coatings deposited by low 49 pressure plasma spraying ${ }^{[14]}$. The effects of the substrate temperature on the hardness, porosity 
50 and thermal expansion of $\mathrm{Al}_{2} \mathrm{O}_{3}$ coatings prepared by the plasma spray process have been

51 reported ${ }^{[15]}$. Fernandez et al. ${ }^{[16]}$ studied the influence of sliding speed and normal load on the

52 wear behavior of plasma-sprayed $\mathrm{Al}_{2} \mathrm{O}_{3}$ coatings. Spraying conditions such as critical plasma

53 spray parameter (CPSP) and distance between the spraying gun and the substrate, which are

54 widely used as variables to quantitatively identify the temperature of spray powders inside the

55 plasma flame, also affect the final coating microstructures and consequently the wear resistance.

56 The critical plasma spraying parameter (CPSP) is expressed as the plasma output power in the

57 numerator and the primary gas (Ar) flow rate in the denominator ${ }^{[17,18]}$. It is well known that

58 when the plasma output power is increased, the particle temperature increases due to increasing

59 plasma jet temperature because it is very sensitive to CPSP. The decrease in the argon flow rate,

60 which leads to an increase in the powder in-flight time, has a similar effect on the particle

61 temperature as the increase in the plasma output power. So CPSP can alter the coating

62 microstructure and properties. Our previous study provided an insight into the wear behavior of

63 plasma-sprayed $\mathrm{Al}_{2} \mathrm{O}_{3}$ coatings prepared using coprecipitation synthesized alumina powders ${ }^{[19]}$.

64 However, such a study has not been reported for alumina coatings prepared by using spray dried

65 alumina powder.

66 The main aim of this work was to prepare plasma sprayable alumina powder by spray drying

67 process and fabricate coatings with three different critical plasma spray parameters using the 68 spray dried alumina powders. It was also aimed at studying the effect of CPSP on the 69 microstructure, wear and corrosion resistance of the plasma sprayed alumina coatings.

70

\section{2. Experimental}


72 Plasma sprayable grade alumina powder was prepared using a laboratory type tall spray dryer

73 (SM Scientech, India) as follows: $350 \mathrm{~g}$ alumina powder (-45 $\mu \mathrm{m}$ sieve, Alcoa) was dispersed in

741 litre of water and $50 \mathrm{~mL}$ of $6 \%$ PVA (Loba Chemie) and was milled for 4 hours using a pot

75 mill and alumina balls. The spray dryer was operated with an inlet temperature of $325^{\circ} \mathrm{C}$, outlet

76 temperature of $145^{\circ} \mathrm{C}$ and air pressure of 2 bars. The obtained spray dried alumina powder was

77 sieved (-25 to $+90 \mu \mathrm{m})$ to remove larger and smaller sized particles before plasma spraying. The

78 spray dried powder was not subjected to any calcination before plasma spraying. Phase

79 formation of alumina powders were confirmed by X-ray diffraction (XRD) using X`Pert Data X-

80 ray diffractometer. Particle size distribution of the powder was analyzed using laser light

81 scattering method (Mastersizer 2000, Malvern Instruments). Flowability of the powder was

82 measured using a Hall flow meter according to ASTM B213-97. The morphology of the powder

83 and surface and cross-sectional microstructures of plasma sprayed alumina coatings were

84 examined using field emission scanning electron microscope (FESEM, Carl Zeiss). Spray dried

85 alumina powders were plasma sprayed on stainless steel substrates using air plasma spraying

86 system (Sulzer Metco-9M). The plasma spray parameters used for spraying alumina powders are

87 listed in Table-I. To improve the adhesion of alumina coatings to stainless steel substrates,

88 Amdry 962 (Sulzer Metco) bondcoat material was sprayed before spraying alumina powder.

89 EDAX analysis showed the following composition for the bondcoat: Al-9.07 wt\%, Cr-23.22

$90 \mathrm{wt} \%, \mathrm{Ni}-67.39 \mathrm{wt} \%$ and Y-0.33 wt\%. Prior to spraying, the substrates were grit blasted (the

91 average size of commercial grit was about $25 \mu \mathrm{m}$ ) and degreased ultrasonically in acetone. For

92 convenience, the plasma sprayed alumina coatings sprayed at CPSP (W/nl.pm) values of 675,

93825 and 937.5 are designated as alumina-1, alumina- 2 and alumina- 3 respectively. 
Microhardness measurements were performed on the cross-sections of the plasma 95 sprayed alumina coatings using microhardness tester (Buehler, Micromet 100) by applying 50 gf 96 load. The microhardness values were measured at ten different places on the cross-section and 97 the average value is reported. For wear studies, alumina powder was plasma sprayed on stainless steel substrates $(35 \mathrm{~mm}$ × $20 \mathrm{~mm}$ x $4 \mathrm{~mm}$ ). The sliding wear test was carried out using 99 reciprocating wear tester (TR-285 M, DUCOM, India) with reciprocating motion against $6 \mathrm{~mm}$ 100 diameter $\mathrm{Al}_{2} \mathrm{O}_{3}$ ball. The wear test was performed with $2 \mathrm{~N}$ load, $1 \mathrm{~Hz}$ frequency, and $15 \mathrm{~mm}$ 101 stroke length for three and half hours. Wear rate was calculated by dividing the wear volume by 102 the product of load applied and sliding distance. The weight loss of the coating and the 103 counterpart alumina balls was measured using an electronic weighing balance (0.0001 g 104 accuracy). The average of three wear tests is reported. Surface roughness $\left(R_{a}\right)$ of the coatings 105 was measured using a roughness profilometer (Taylor Hobson).

Corrosion behavior of plasma sprayed alumina coatings deposited at three different 107 CPSPs on stainless steel coupons were conducted using CHI 604 2D electrochemical 108 workstation. The test was carried out in deaerated $3.5 \mathrm{wt} \%(0.6 \mathrm{M}) \mathrm{NaCl}$ solution $(200 \pm 2 \mathrm{~mL})$. 109 A conventional three electrode cell was used; which was equipped with alumina coated stainless 110 steel coupon with an active area of $1 \mathrm{~cm}^{2}$ as working electrode, platinum foil and saturated 111 calomel electrode (SCE) were used as counter and reference electrodes respectively. The edges 112 of the coupons were also masked using lacquer to avoid crevice corrosion. Prior to the corrosion 113 tests, samples were washed in distilled water and ethanol, and then dried in warm air. The 114 reference electrode was connected to a Luggin capillary and its tip was placed very close to the 115 surface of the working electrode to minimize IR drop. The working electrode was immersed in $116 \mathrm{NaCl}$ solution for an hour in order to establish the open circuit potential (EOCP). The system 
117 was allowed to attain open circuit potential then the upper and lower potential limits of linear 118 sweep voltammetry were set at $\pm 200 \mathrm{mV}$ with respect to the EOCP. The sweep rate was $1 \mathrm{mV} / \mathrm{s}$. 119 The corrosion potential $\mathrm{E}_{\text {corr }}$, corrosion current density $\mathrm{i}_{\text {corr }}$ and polarization resistance $\mathrm{Rp}$ were 120 deduced from the Tafel plot. The polarization resistance was obtained using the Stern-Geary 121 equation:

$$
R_{p}=\left[\frac{b_{a} b_{c}}{2.303\left(b_{a}+b_{c}\right)}\right]\left[\frac{1}{i_{c o r r}}\right]
$$

where $b_{a}$ and $b_{c}$ are Tafel slopes or the Tafel constants, expressed in $\mathrm{mV} / \mathrm{dec}$.

\section{Results and Discussion}

\subsection{Characterization of Spray dried Alumina Powder}

127 The spray dried alumina powder had flowability of $70 \mathrm{~s} / 0.050 \mathrm{~kg}$. The spray dried alumina 128 powder possessed mostly spherical shaped particles as shown in the FESEM images (Fig. 1 a \& 129 b). Most of the powders were perfectly spherical in shape. A higher magnification FESEM image 130 (1c) of spray dried single alumina particle consisted of smaller sized particles which indicate 131 each particle to be a constituent of smaller sized particles. Fig. 2 shows the particle size 132 distribution of spray dried alumina powder. The particle size distribution curve of spray dried 133 alumina powder showed a narrow size distribution with an average agglomerated particle size of $13441 \mu \mathrm{m}$ which is suitable for plasma spraying. Fig. 3 shows the powder X-ray diffraction pattern 135 of spray dried alumina powder. The pattern confirmed the formation of $100 \% \alpha$-alumina and the 136 diffraction peaks were sharper and the pattern matched exactly with the starting alumina powder. 


\subsubsection{Microstructure of the coatings}

139 Fig.4 shows the surface FESEM images of the surfaces of as plasma sprayed alumina coatings. 140 The surface FESEM image of spray dried alumina-1 coating exhibited large number of splats 141 along with large number of unmelted particles. Some splats appeared like a custard apple 142 containing well fused particles (Fig.4a). The appearance of such features may be attributed to the 143 explosion of finer and smaller sized particles due to insufficient plasma power. Such features

144 were not observed with plasma sprayed alumina coatings deposited using co-precipitation 145 synthesized powder ${ }^{[19]}$. The presence of such features would have resulted in porous and 146 rougher alumina-1 and alumina-2 coatings. However, the extent of such features was reduced in 147 alumina-2 (Fig. 4b) and finer alumina particles were observed. On the other hand alumina-3 148 coating exhibited mostly fully melted splats along with very few alumina particles; exploded 149 splats were not observed as in the other two coatings (Fig. 4c). Higher magnification FESEM 150 images of the splats showed some cracks and pores typical of plasma sprayed coatings. Fig.5 151 shows the cross-sectional FESEM images of plasma sprayed alumina coatings. From the images 152 it is observed that the density of the coatings varied as follows alumina- $3>$ alumina- $2>$ alumina-

153 1. Alumina-1 coating had more of unmelted / partially melted regions compared to alumina-2 154 and alumina-3 coatings. The coating thickness was also slightly higher for alumina-3 coating and 155 this may be attributed to the complete melting of most of the alumina particles in the high 156 temperature plasma. All the coatings showed bimodal distribution.

\section{$157 \quad 3.2 .2 . X$-ray analysis of plasma sprayed alumina coatings}

158 Fig.6 shows the XRD patterns of plasma sprayed alumina coatings prepared from spray dried $\alpha-$ 159 alumina powder at different CPSPs. The coating formed with lower CPSP retained $\alpha$-form of 
160 alumina. Interestingly, the coating obtained with highest CPSP (alumina-3) showed the presence

161 of $\gamma$-alumina (400) peak. Commonly $\gamma-\mathrm{Al}_{2} \mathrm{O}_{3}$ nucleates in preference to $\alpha-\mathrm{Al}_{2} \mathrm{O}_{3}$ during rapid

162 solidification of liquid droplets ${ }^{[20-22]}$. With increasing CPSP, the intensity of the $100 \%$ alpha 163 alumina (113) peak and (024) increased. Interestingly, $\alpha-\mathrm{Al}_{2} \mathrm{O}_{3}$ (208) peak intensity decreased 164 with increasing CPSP.

\section{3.2.3. Microhardness and roughness of plasma sprayed alumina coatings}

166 Alumina-1 exhibited lowest microhardness followed by alumina-2 and alumina-3 exhibited 167 highest microhardness (Fig. 7). The properties of the coatings were affected by the high 168 incidence of semi-molten/unmelted particles. Porosity was higher at the lower spraying energies, 169 where the semi-molten particles are less deformed. At higher spraying energies, molten material 170 of high diffusivity would fill the asperities and gaps of the previously deposited layers, leading to 171 lower porosities. The microhardness increased with spraying power (Fig.7 ), possibly as a result

172 of the decreased porosity ${ }^{[23]}$. The higher hardness is attributed to the complete melting of the 173 alumina particles at higher CPSP. The lower microhardness of alumina-1 is attributed to the 174 presence of higher fraction of unmelted or partially melted zones present in the microstructure of 175 the plasma coating. The surface roughness of alumina-1 coating was highest and that of alumina1763 was the least (Fig.8).

\section{$177 \quad 3.2 .4$. Wear resistance of plasma sprayed alumina coatings}

178 The wear data obtained for all the three plasma sprayed alumina coatings and the alumina 179 counterpart balls are tabulated in Table-II. Alumina-3 coating and its corresponding alumina ball 180 counterparts exhibited the lowest wear loss. Larger wear rates are usually caused by the removal 181 of entire lamellae or part of them. The low cohesive strength and the presence of inter-lamellar 
182 cracks could have contributed to larger wear rate of alumina- ${ }^{[7]}$. At higher CPSP most of the 183 particles are fully melted in the spray jet. In case of coatings sprayed with medium CPSP, there 184 are sufficient numbers of partially melted or unmelted regions that resemble the constituent 185 alumina particles of the agglomerates.

In general, hardness influences the wear resistance of plasma-sprayed coatings, and 187 microstructure, ductility, toughness, and pores present in the coating also play a role in the wear 188 process. The coefficient of friction (COF) was $\sim 0.7$ for all the three coatings irrespective of the 189 different CPSPs used for plasma spraying. The predominant wear mechanism was of abrasive 190 type and caused the material to delaminate owing to the high pressure exerted by the ball on the 191 coating.

192 The values of the corrosion potential (Ecorr) and the corrosion current density (icorr) were 193 extracted from the curves using the Tafel extrapolation method. The corrosion potential, 194 corrosion current density and the polarization resistance obtained for the plasma sprayed alumina 195 coatings by potentiodynamic polarization studies are tabulated in Table-III. The corrosion 196 current density is an important parameter used for evaluating the kinetics of the corrosion 197 reaction. Corrosion protection is inversely proportional to the corrosion current density. Lower 198 the corrosion current density, higher will be the corrosion resistance. The corrosion current 199 density followed the following order: alumina-3 $<$ alumina- $<$ alumina- $1<$ stainless steel 200 substrate. The corrosion current density for the alumina-3 coating was very low which also 201 indicates superior corrosion resistance of the coating. In general the $\mathrm{E}_{\text {corr }}$ values shifted to more 202 negative side compared to the substrate indicating improved corrosion resistance of the coatings 203 over the substrate. The $\mathrm{R}_{\mathrm{p}}$ value of alumina-3 coating was the highest implying better corrosion 
204 resistance of the coating compared to other coatings. The improved corrosion resistance of

205 alumina-3 is attributed to the dense nature of the coating.

206

207

\section{Conclusion}

208 Plasma sprayable grade alumina powder was prepared by spray drying process. The powders 209 were plasma sprayed at three different critical plasma spray parameters (CPSP). From this study 210 it is evident that CPSP influences the microstructure, microhardness and wear behavior of the

211 plasma sprayed alumina coatings. The surface roughness decreased with increasing CPSP and 212 the density of the coatings increased with increasing CPSP. The wear and corrosion resistance of 213 alumina coatings increased with increasing CPSP. The coating that was plasma sprayed at higher 214 CPSP showed traces of $\gamma$-alumina along with $\alpha$-alumina. The microhardness of the coatings 215 increased with increasing CPSP and was in the range of 1000-2100 $\mathrm{HK}_{50 \mathrm{gf}}$. The alumina coating, 216 plasma sprayed at the highest CPSP showed lower wear rate and higher corrosion resistance 217 compared to the other two coatings which is attributed to the dense nature of the coating. The 218 surface roughness of the coatings decreased with increasing plasma power.

\section{Acknowledgements}

221 The authors acknowledge the financial assistance received from the Network project on

222 Nanostructured Advanced Materials (NWP-00-51-01) from CSIR-NML. The authors thank the 223 Director, NAL and Head, SED for their constant encouragement. The authors thank Dr. Geetha 224 Manivasagam, VIT, Vellore for the wear studies. Help received from Siju in FESEM study is 225 acknowledged. 
$23455(2004)$.

235 [5] F. Rastegar, D.E. Richardson, Surf. Coat. Technol., 90, 156-193 (1997).

236 [6] K.A. Khor, Y.W. Gu, Thin Solid Films, 372, 104-113 (2000).

237 [7] R.S Lima and B.R Marple, J. Thermal Spray Technol., 16(1) , 40-63 (2007).

238

239

240

241

242

243

244

245

246 (2005).

247 [13] T. Lampke,D. Meyer, G. Alisch, B. Wielage, H. Pokhmurska, M. Klapkiv, M. Student, $248 \quad$ Mater. Sci., 46 (5), 591-598 (2011).

249 [14] E.J. Young, U. Eli Mateeva, J. J. Moore, B. Mishra, M. Loch, Thin Solid Films, 377-378 $250 \quad 788-792(2000)$. 
251 [15] O. Sarikaya, Mater. Design, 26, 53-57 (2005).

252 [16] J.E. Fernandez. R. Rodriguez, Y. Wang. R. Vijande. R. Rincon., Wear 181- 183 417-425

253 (1995).

254 [17] E.P. Song, J. Ahn, S. Lee, N.J. Kim, Surf Coat Technol., 202 (2008) 3625-3632.

255 [18]. S. Yugeswaran, V. Selvarajan, M. Vijay, P.V. Ananthapadmanabhan, K.P. Sreekumar, , 256 Ceram. Int., 136 (2010) 141-149.

257 [19] S.T. Aruna, N. Balaji, Jyothi Shedthi, V.K. William Grips, Surf. Coat. Technol.., 208, 258 (2012) 92-100.

259 [20]. Xinhua Lin, Yi Zeng, Xiaming Zhou, Chuanxian Ding., Mater. Sci. Eng., A 357 228-234.

260

261

262

263

264

265

266

267

268

269

270

271

272

273
[21] D. Wang, Z. Tian, L. Shen, Z. Liu, Y. Huang, Surf Coat Tech.,. 203, 1298-1303(2009).

[22]. R. Mcpherson, O J. Mater. Sci.,, 15 , 3141-3149 (1980).

[23] H. Luo, D. Goberman, L. Shaw, M. Gell, Mater. Sci. Eng. A346, 237-245 (2003). 
Table-I. Plasma spray parameters used for bondcoat and spray dried alumina powder

\begin{tabular}{lll}
\hline Plasma spray parameters & Bond coat & Alumina \\
\hline Argon Flow (NLPM) & 40 & 40 \\
Hydrogen Flow (NLPM) & 9 & 7 \\
Amps (A) /Volts (V) & $550 / 60$ & $450,550,625$ / 60 \\
CPSP (NLPM) & 825 & $675,825,937.5$ \\
Carrier gas Flow (SCFH) & 15 & 15 \\
Pre Heat / Spray passes & $2 / 5$ & $2 / 14$ \\
Powder Feed rate (g/min) & 10 & 15 \\
Cooling air Pressure (bar) & 2 & 2 \\
Spray distance (cm) & 25 & 15 \\
Gun speed (mm/s) & 800 & 800 \\
\hline
\end{tabular}

275

276

277 Table. II. Wear rate of plasma sprayed spray dried alumina coatings

\begin{tabular}{|l|l|l|l|l|}
\hline \multirow{2}{*}{ Sample ID } & \multicolumn{2}{|c|}{ Volume loss $\left(\mathrm{mm}^{3}\right)$} & \multicolumn{2}{c|}{ Wear rate $\mathbf{m m}^{3} / \mathrm{Nm}$} \\
\cline { 2 - 5 } & \multicolumn{1}{|c|}{ Coating } & \multicolumn{1}{c|}{ Ball } & Coating & Ball \\
\hline \multirow{2}{*}{ Alumina-1 } & 1.859 & 0.507 & $1.259 \times 10^{-3}$ & $1.052 \times 10^{-4}$ \\
\hline Alumina-2 & 0.728 & 0.126 & $5.09 \times 10^{-4}$ & $8.76 \times 10^{-5}$ \\
\hline Alumina-3 & 0.452 & 0.101 & $3.15 \times 10^{-4}$ & $7.01 \times 10^{-5}$ \\
\hline
\end{tabular}


284 Table-III. Potentiodynamic polarization data of plasma sprayed alumina coatings

\begin{tabular}{|l|l|l|l|l|}
\hline Samples & OCP(V) & Ecorr $(\mathbf{V})$ & Icorr $\left(\mu \mathbf{A} / \mathbf{c m}^{2}\right)$ & $\mathbf{R p}\left(\boldsymbol{\mathbf { c m } ^ { 2 }}\right)$ \\
\hline Substrate & -0.177 & -0.199 & 9.717 & 3661 \\
\hline Alumina-1 & -0.294 & -0.331 & 0.6864 & 51399 \\
\hline Alumina-2 & -0.236 & -0.212 & 0.3647 & 54702 \\
\hline Alumina-3 & -0.310 & -0.214 & 0.1129 & 340454 \\
\hline
\end{tabular}




\section{Figure Captions}

291 Fig.1. FESEM images of spray dried alumina particles taken at various magnifications (a) 1.5KX

292 (b) $6 \mathrm{KX}$ (c) $30 \mathrm{KX}$

293 Fig.2. Particle size distribution of spray dried alumina powder showing a narrow size distribution

294 Fig.3. XRD analysis of spray dried alumina powder.

295 Fig. 4. FESEM surface images of plasma sprayed alumina coatings at different CPSP s (a)

296 alumina-1, (b) alumina-2 and (c) alumina-3.

297 Fig. 5. FESEM images of plasma sprayed spray dried alumina coatings cross-section at different 298 CPSP (a) alumina-1, (b) alumina-2 and (c) alumina-3.

299 Fig. 6. XRD patterns of plasma sprayed alumina coatings at different critical plasma spray 300 parameter (a) alumina-1, (b) alumina-2 and (c) alumina-3.

301 Fig. 7. Histogram showing the Knoops microhardness of the alumina coatings plasma sprayed at 302 different CPSPs.

303 Fig. 8.Histogram showing the surface roughness of the surface and worn out regions of APS 304 alumina coatings plasma sprayed at different CPSPs. 


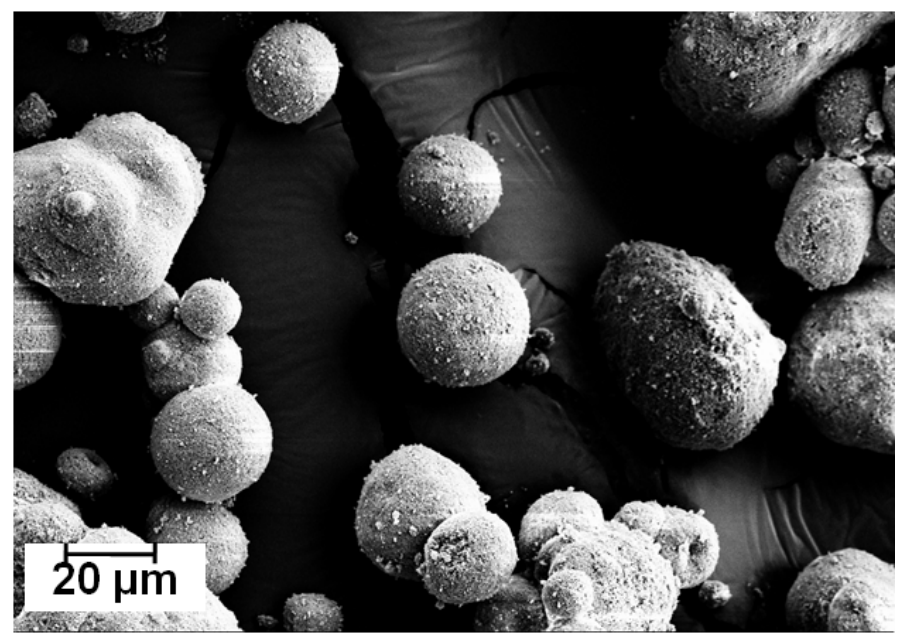

Fig.1a

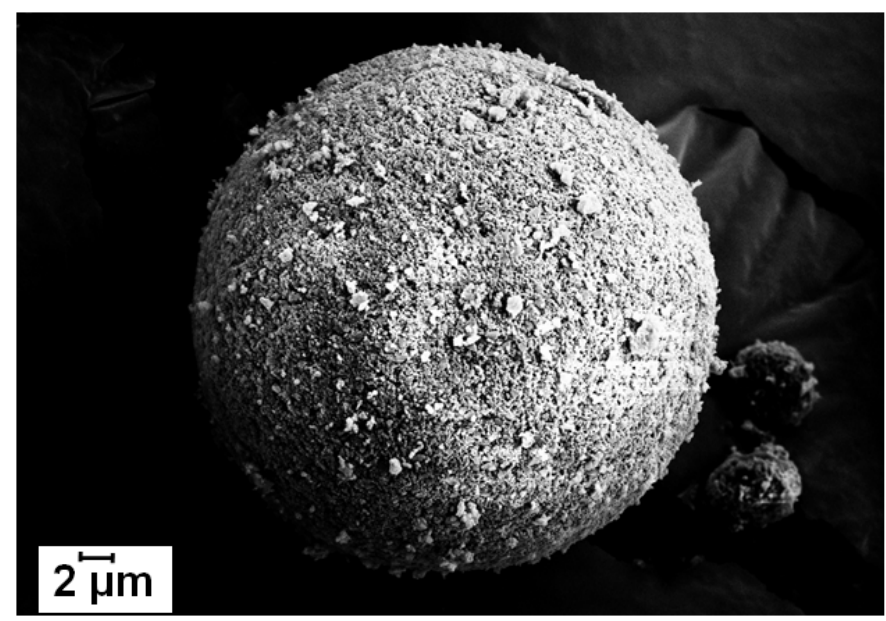

Fig.1b

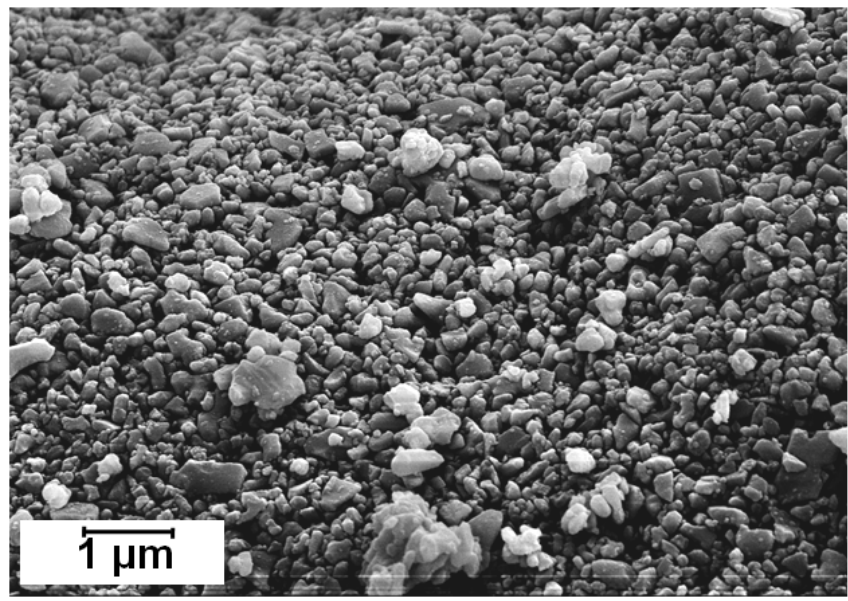

Fig.1c 


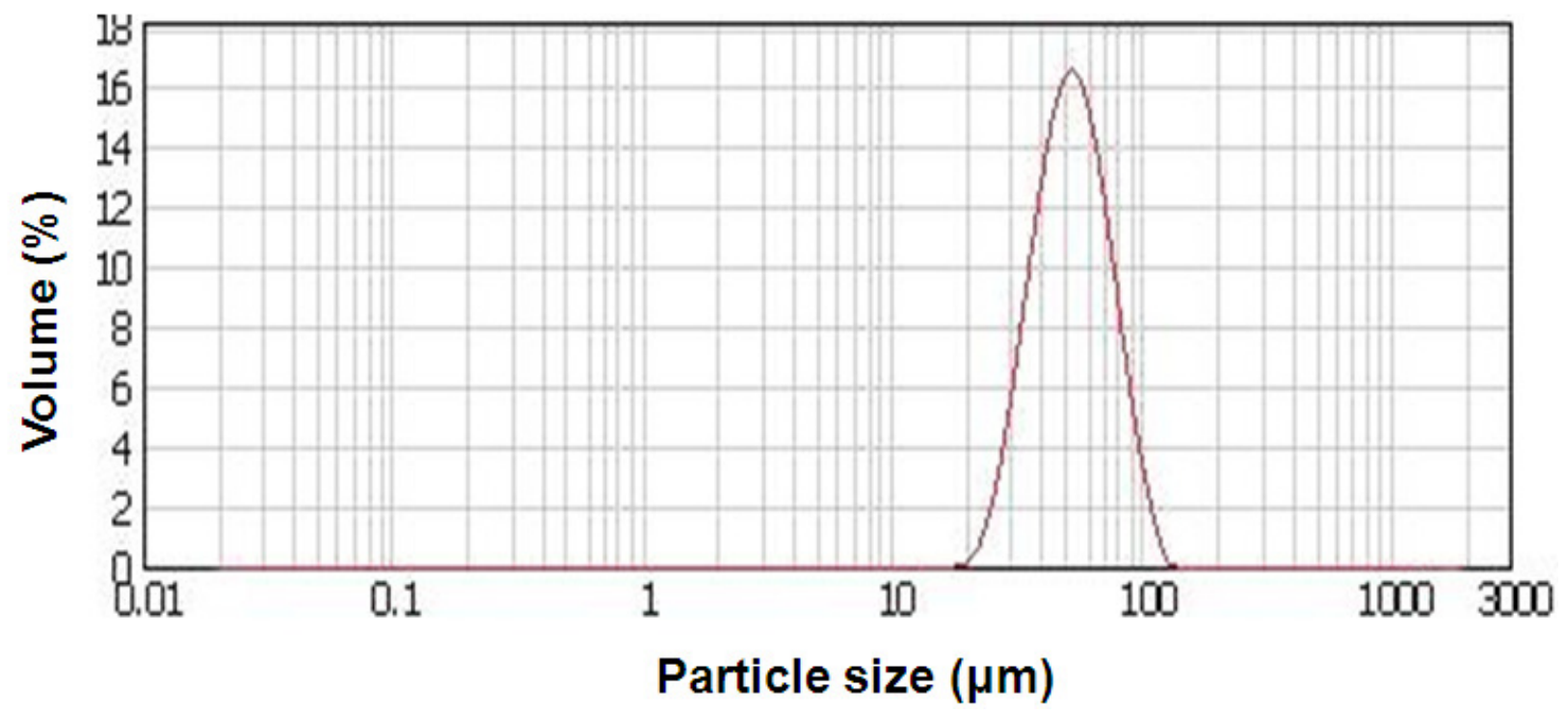

Fig.2

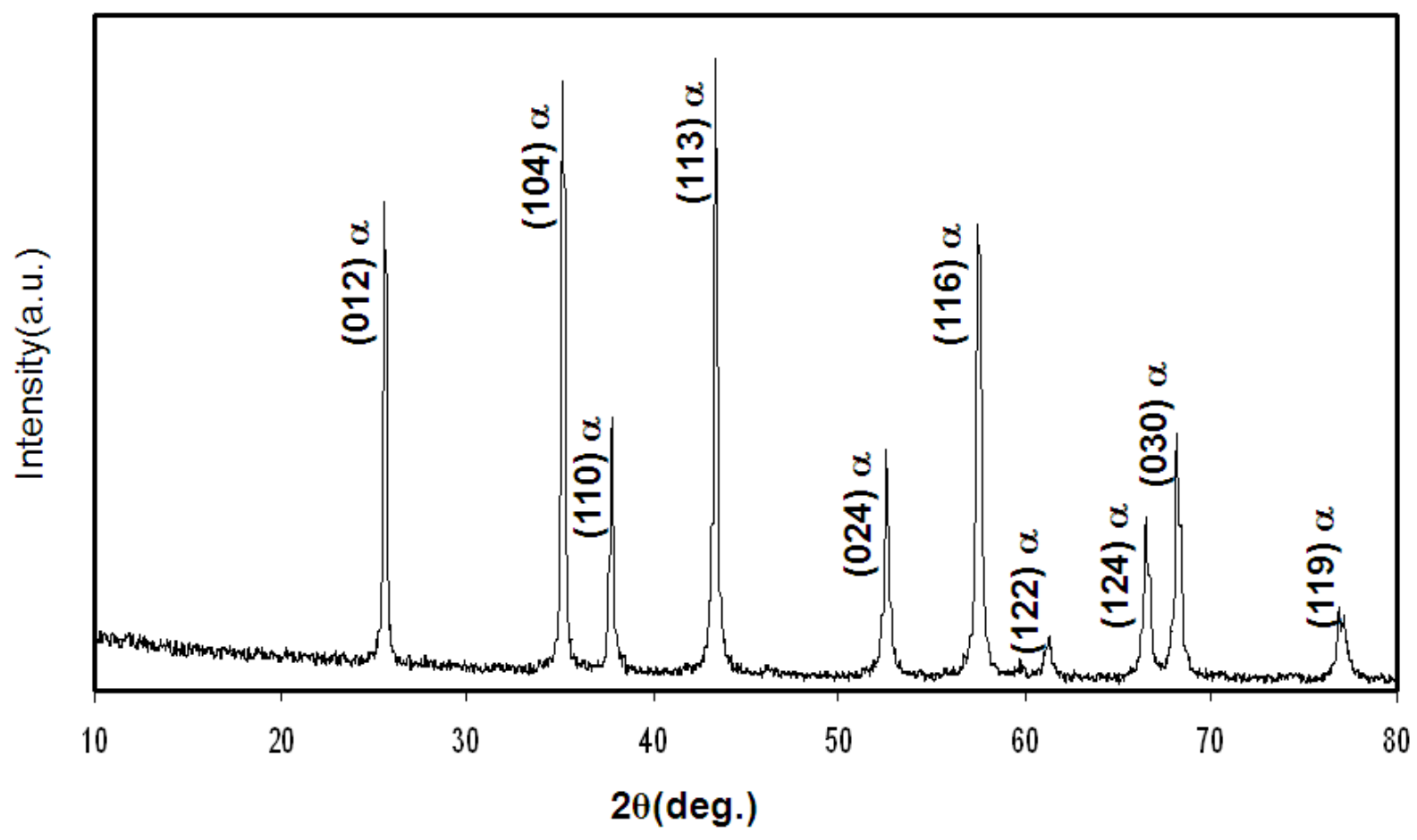

Fig.3 


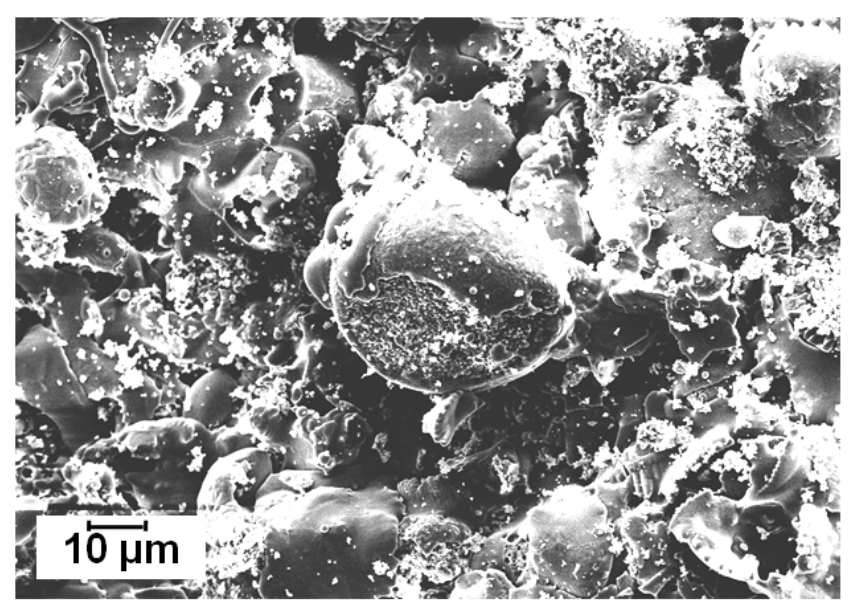

Fig.4a

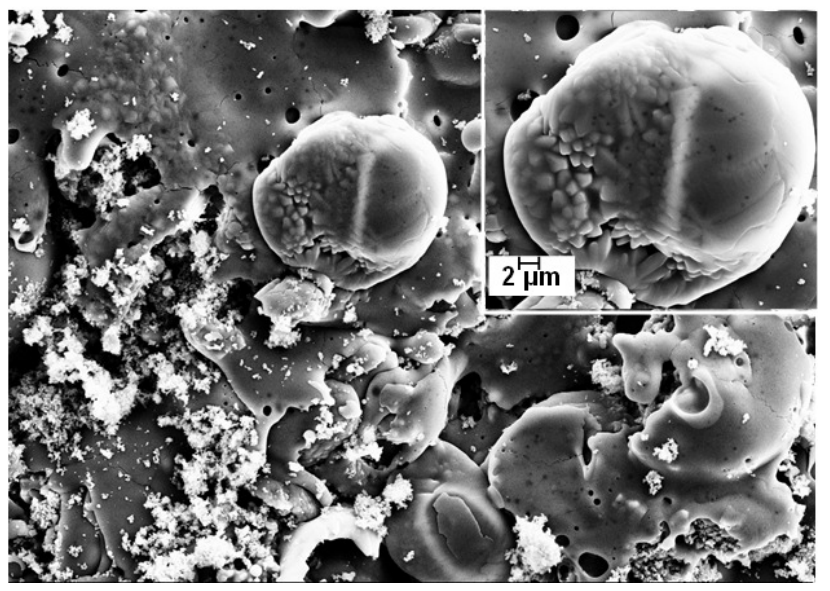

Fig.4b

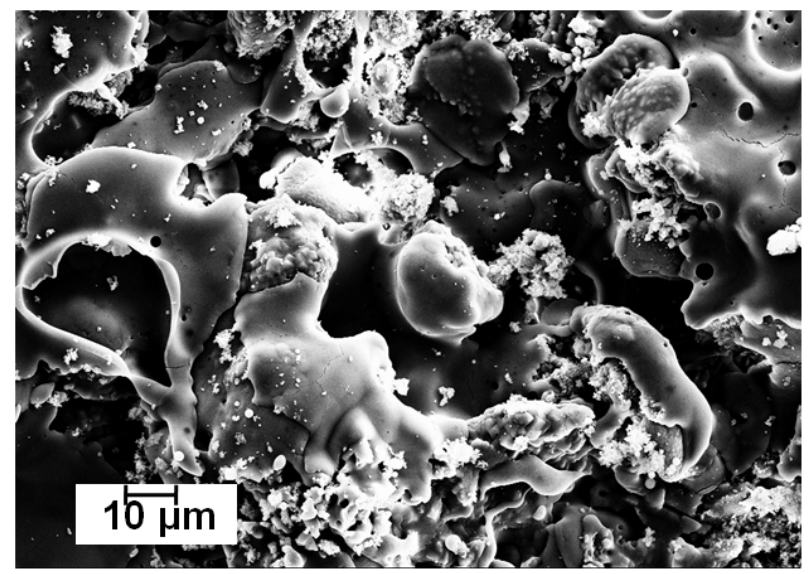

Fig.4c 

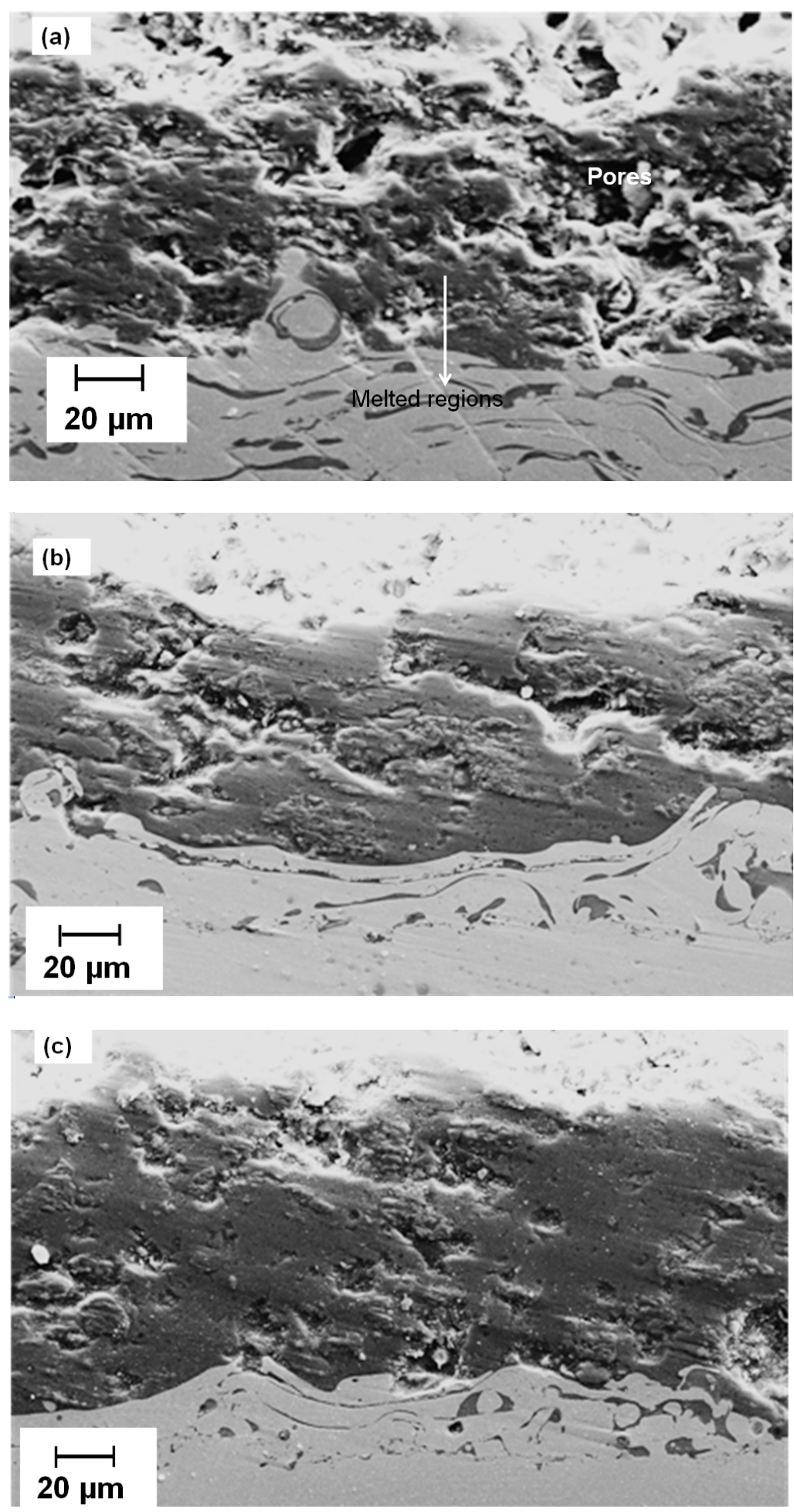

Fig.5 


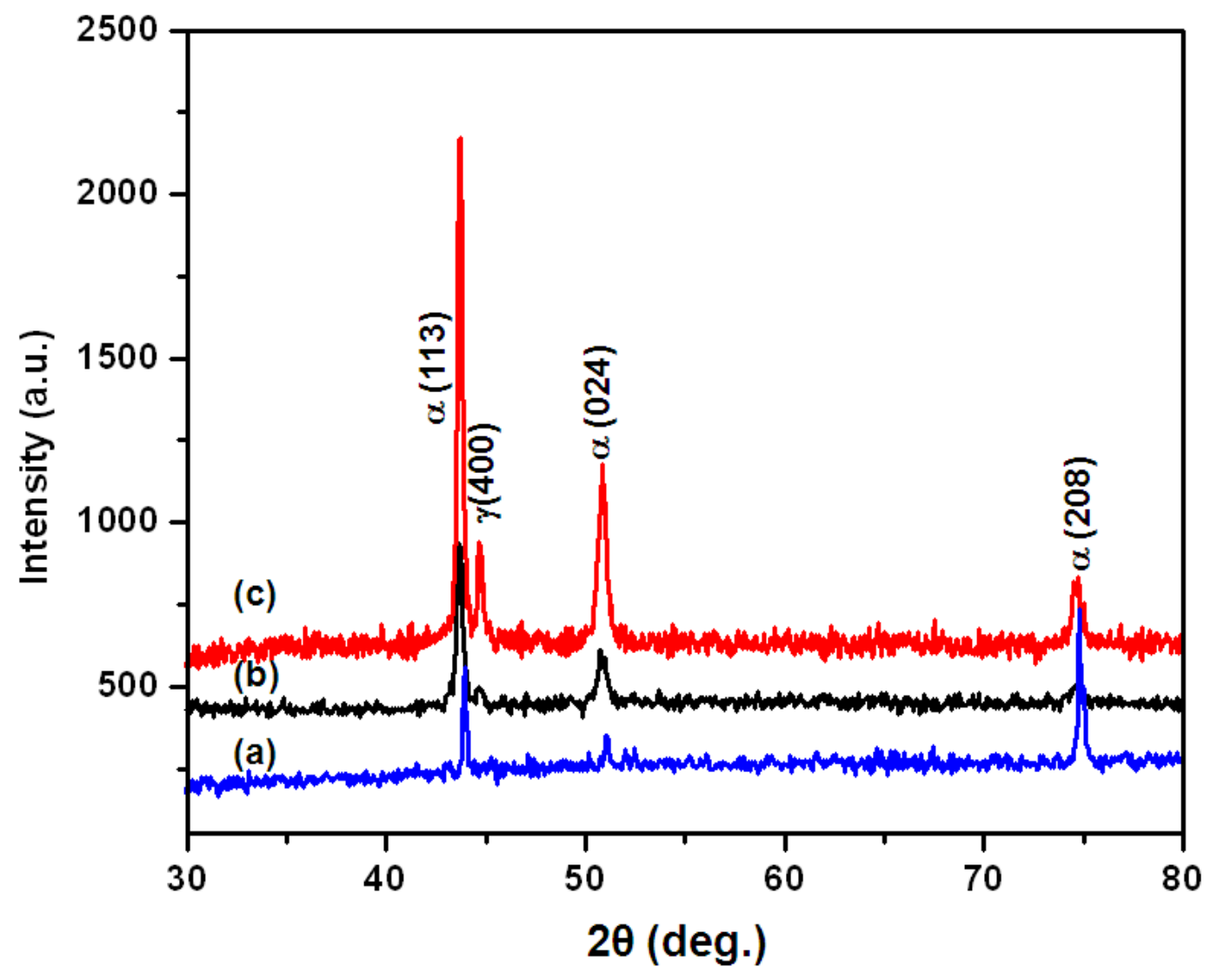

Fig.6 


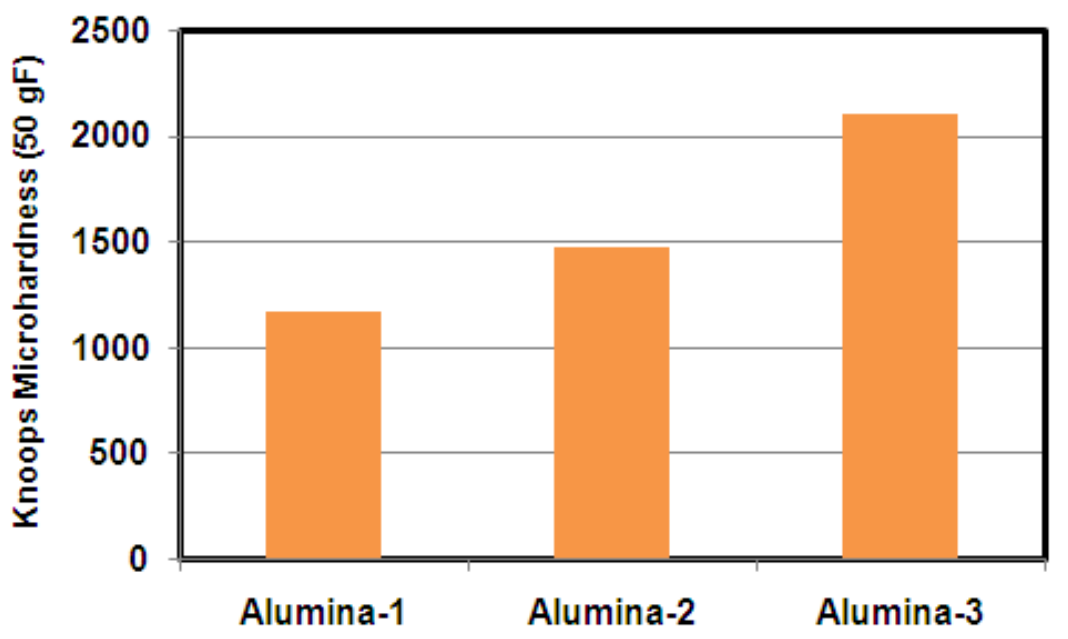

Fig.7 


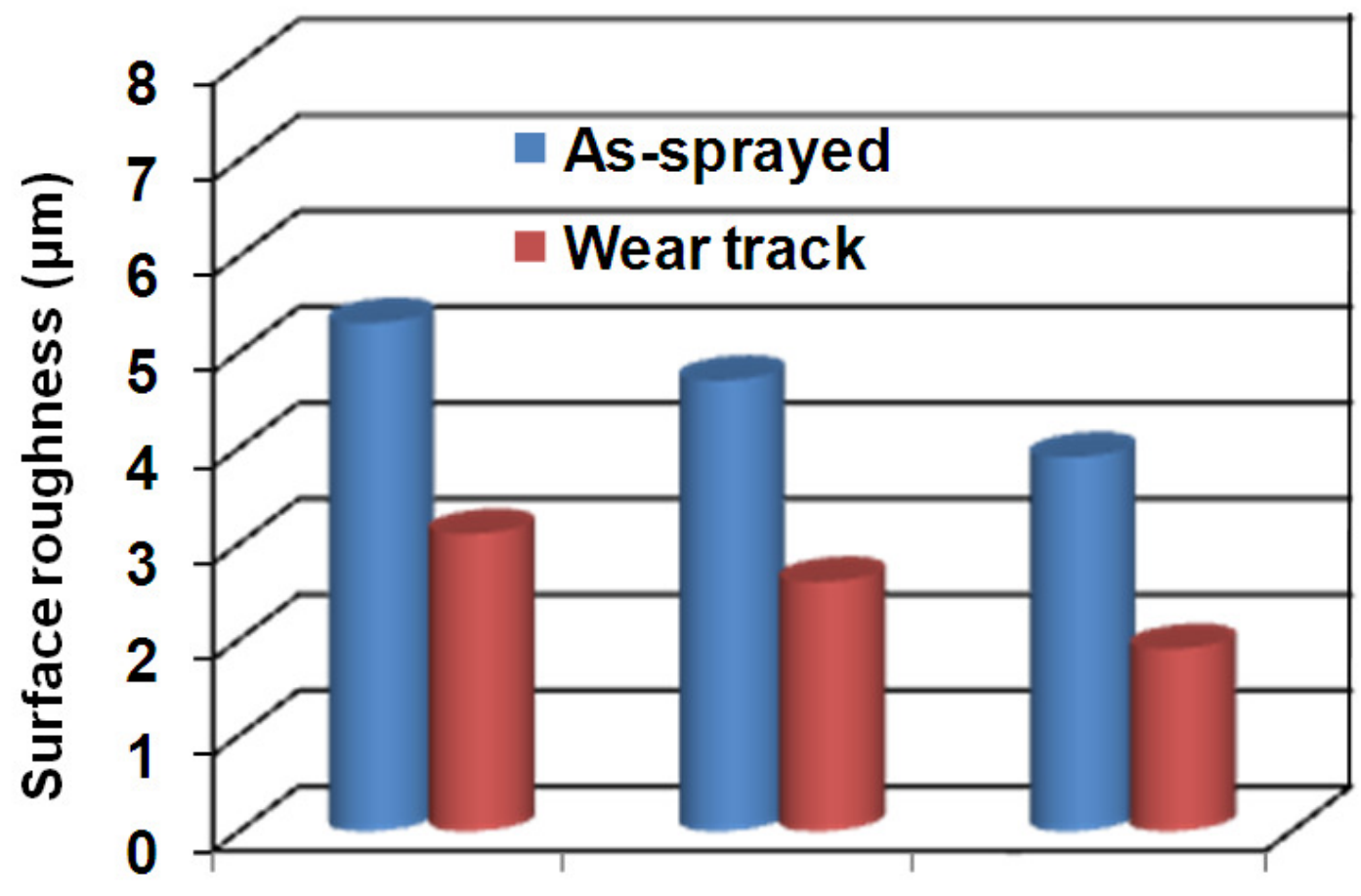

Alumina-1 Alumina-2 Alumina-3

Fig.8

307

308 